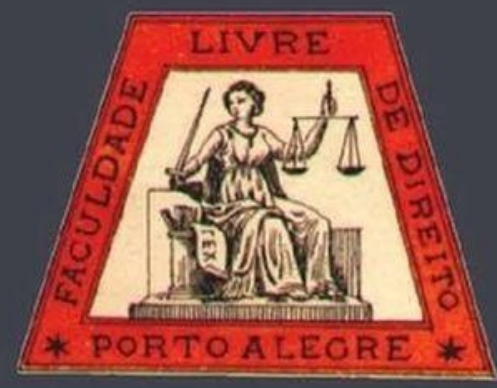

\title{
Método científico no Direito segundo Pontes de Miranda
}

Scientific method in Law according to Pontes de Miranda

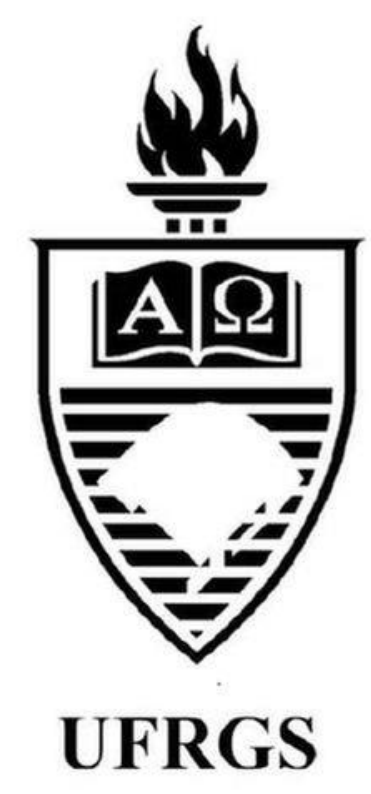

Saulo Monteiro Martinho de Matos

Universidade Federal do Pará

Douglas Domingues Gabriel Neto

Universidade Estácio de Sá 


\title{
Método científico no Direito segundo Pontes de Miranda
}

\author{
Scientific method in Law according to Pontes de Miranda
}

Saulo Monteiro Martinho de Matos*

Douglas Domingues Gabriel Neto**

\section{REFERÊNCIA}

MATOS, Saulo Monteiro Martinho; GABRIEL NETO, Douglas Domingues. Método científico no Direito segundo Pontes de Miranda. Revista da Faculdade de Direito da UFRGS, Porto Alegre, n. 40, p. 256-273, ago. 2019.

\section{RESUMO}

Este estudo é uma contribuição à recepção do pensamento naturalista brasileiro do início do século XX. Como a primeira grande discussão da Ciência Jurídica Brasileira foi metodológica e Pontes de Miranda desempenhou nela um papel de vulto, há que se indagar no que propôs, por que essa proposta não vingou e o que seria necessário para que fosse implementada. O objetivo deste artigo é expor sua proposta metodológica para a Ciência Jurídica. $\mathrm{O}$ método empregado foi documental, dedutivo e histórico, porque pretende reconstituir os argumentos de um autor do início do século XX. O artigo levanta quatro hipóteses: o regalismo foi o problema-motivo da proposta metodológica de Pontes (seção 1); Pontes rejeitou os métodos contemporâneos a seu pensamento, porque os considerou subjetivos (seção 2); para eliminar sua subjetividade, propôs a identidade funcional (seção 3) e metodológica (seção 4) dos atores jurídicos, adaptando o método científico ao Direito. Os resultados obtidos foram que (1) o método proposto só poderia ser implementado após uma reviravolta indiscriminada na maneira com que o Direito é pensado; (2) a crítica de Lopes (inconsistência de princípios e prática naturalista) não cabe para o pensamento de Pontes de Miranda, porque ele pressupunha um auxílio mútuo dos juristas, e não uma concentração de forças para a revelação solitária do direito. A falta de empiria em seus escritos se justifica pelo auxílio dos juristas, que, juntos, se ajudam na melhor da compreensão do Direito a partir do método científico, como foi feito na Física.

\section{PALAVRAS-CHAVE}

Pontes de Miranda. Metodologia jurídica. Ciência do Direito. Regalismo.

\section{ABSTRACT}

This study is a contribution to the reception of Brazilian naturalist thought from the beginning of the $20^{\text {th }}$ Century. Since Brazilian Legal Science's first debate was methodological and Pontes de Miranda played an important role on it, it is necessary to question his proposition, why it did not succeed, and what would be necessary for it to become widely practiced. This article's goal is to present his methodological approach to the Science of Law. The method used in this work was documental, deductive, and historical. It starts with four hypotheses: regalism was the problem-motive behind Pontes' methodological approach (section 1); Pontes rejected the methods of his age, for he considered them subjective (section 2); to avoid such subjectivity, Pontes in turn proposed a functional (section 3) and methodological (section 4) identity between legal actors, adapting the scientific method to legal studies. The research showed the following results: the described method would only be applied after a major overturn in the way Law is thought; Lopes' critique suggesting that Pontes' work is inconsistent with his premises is unfounded, since it presupposed collaboration between scholars instead of a concentration of efforts in order to achieve a solitary comprehension of Law. The lack of empiricism in his works is justified by the help of other scholars, which, united, collaborate with one another to a better understanding of Law through the scientific method, as it was done in Physics.

\section{KEYWORDS}

Pontes de Miranda. Legal methodology. Legal science. Regalism.

\footnotetext{
* Doutor e Professor Visitante do Departamento de Filosofia do Direito e Filosofia Social da Universidade de Göttingen (Alemanha). Professor Adjunto de Ética, Teoria do Direito e Hermenêutica Jurídica da Faculdade de Direito e do Programa de Pós-gradução em Direito da Universidade Federal do Pará.

** Especializando em Direito Contratual, Universidade Estácio de Sá. Advogado. Bacharel em Direito pela Universidade Federal do Pará.
} 


\section{SUMÁRIO}

Introdução. 1. O problema da interferência da vontade na elaboração do Direito. 2. As tentativas frustradas de resolução pelos métodos subjetivos. 2.1 Método escolástico. 2.2 Método racionalista. 2.3 Método sistemático. 2.4 Método analógico. 2.5 Método institucionalista. 2.6 Método histórico. 2.7 Método pragmático. 3. Democratização da revelação do Direito. 4. As três fases do método científico. 4.1 Observação. 4.2 Indução. 4.3 Experimentação. Conclusão. Referências.

\section{INTRODUÇÃO}

Apesar de as primeiras faculdades de Direito do Brasil terem sido instaladas ainda no tempo do Império, foi só na Primeira República (início do século XX) que começou a primeira discussão de Filosofia do Direito no Brasil; e ela foi sobre o método da Ciência Jurídica (LOPES, 2014, passim). Na esteira do que ocorria nos Estados Unidos da América e na Europa continental, o movimento do positivismo empiricista ou naturalismo ${ }^{1}$ questionava a falta de cientificidade do jusnaturalismo racionalista e do conceitualismo, predominantes nas Faculdades de Direito do Ocidente até o fim do século XIX. O Brasil fez parte desse movimento filosófico e científico por meio de autores como Sílvio Romero, Tobias Barreto e Pontes de Miranda.

Por causa da avalanche positivista que dominava o cenário intelectual brasileiro de então, uma das propostas mais convincentes era a cientificista. Clóvis Bevilacqua, o grande nome por trás do Código Civil de 1916, propunha que os juristas, consultando as novas ciências humanas europeias, deveriam se inspirar em seus resultados empíricos a fim de legislar e avaliar a legislação. De fato, naquela época, a promulgação de normas ainda era vista como o

\footnotetext{
1 Os termos "naturalismo jurídico", "positivismo empiricista" ou "empirismo" são utilizados, aqui, como sinônimos para contemplar todas as teorias que tratam o direito como um fato social, cuja existência pode ser comparada com a existência de coisas físicas ou psicológicas, e com um método científico, normalmente de inspiração sociológica, apropriado para verificação de tais fatos.
}

grande distintivo do Direito $^{2}$, um ponto que Pontes de Miranda colocará em xeque na sua teoria, como se verá na seção 4 .

E, dentre os naturalistas de então, certamente o mais famoso é o mesmo Pontes de Miranda, seja por sua vasta obra, seja por seu prestígio. ${ }^{3}$ E, como todo autor famoso, Pontes de Miranda é também um autor injustiçado, porque, com obra tão numerosa, dificilmente haverá quem a tenha lido toda. Consequentemente, será difícil bem delinear seu pensamento, em especial se forem desconsiderados seus pressupostos, o que parece ser a tendência ao se tratar dele.

Alguns estudiosos mantêm uma imagem de Pontes de Miranda enquanto um autor que pregava o método científico mas escrevia sobre dogmática. José Reinaldo Lima Lopes (2014, p. 32-33), por exemplo, afirma que Pontes de Miranda se baseia em um método misto entre naturalismo no campo da teoria do direito e conceitualismo no domínio da dogmática,

\footnotetext{
2 Essa concepção pode ser confirmada ainda hoje em manuais de Direito Constitucional, em especial quando os doutrinadores citam Montesquieu, cuja ordenação dos poderes iniciava com o Legislativo. Esse tipo de pensamento persiste mesmo na Constituição de 1988, na medida em que também o primeiro Poder examinado no Título da Organização dos Poderes é o Legislativo. É claro que a Constituição não poderia iniciar com os três poderes simultaneamente e mesmo o seu art. $2^{\circ}$ prescreve que sejam independentes e harmônicos, mas é um sintoma que o Legislativo ainda fique sendo algo como um primeiro entre iguais (primus inter pares), ao menos em termos de elaboração jurídica. Ademais, esse sintoma não deixa de ser também um rastro da tradição romanogermânica, a que pertence o Direito brasileiro.

3 Ao lado de Pontes de Miranda, Lopes (2014, p. 47) inclui Hermes Lima como outro jurista da época que possui grande influência até hoje no pensamento jurídico brasileiro.
} 
semelhante ao que pode ser observado na Europa continental no mesmo período. Ele seria, então, um pensador inconsequente, porque, ainda que propusesse algo na teoria, sua prática seria outra.

Pensadores hipócritas não são, como se sabe, bem vistos.

Não obstante essas acusações, suas obras dogmáticas são lidas até hoje, o que não se pode dizer das mais teóricas, talvez pelo testemunho uníssono de certos autores de que a teoria de Pontes seria algo como um apêndice à maneira como ele tratava o Direito, o que está longe de ser a verdade.

De fato, Pontes não é, ao contrário do que dizem os autores citados, um pensador inconsequente ou paradoxal. Para se compreender isso, porém, é preciso bem compreender os pressupostos de sua teoria e, consequentemente, de sua metodologia. O objetivo deste estudo consiste em reconstruir os pressupostos filosóficos do naturalismo ou positivismo empiricista de Pontes de Miranda, a fim de elucidar as suas críticas, a sua proposta metodológica e alguns limites da sua teoria. É importante salientar que não há o escopo de defender a teoria de Pontes de Miranda como proposta metodológica para o direito, ou seja, de propor o naturalismo de Pontes como solução para os problemas relacionados com a metafísica e epistemologia jurídica. Até porque uma tal empreitada pressuporia um debate muito mais amplo, envolvendo problemas e autores não discutidos ao longo deste estudo.

A proposta, aqui, é muito menos ambiciosa: parte-se da constatação de que o pensamento filosófico brasileiro é, amiúde, negligenciado na academia nacional e que a tarefa da Filosofia do Direito consiste, também, em compreender os principais debates realizados na história das ideias jurídicas no Brasil. Todavia, ao invés de discutir Pontes de Miranda em seu contexto social ou intelectual, o estudo procurou explicitar os conceitos fundamentais de sua teoria do direito, valorizando a sua proposta teórica, consciente das limitações desta metodologia.

Isto posto, o presente artigo pretende demonstrar que Pontes de Miranda seguiu à risca seus objetivos, ainda que não tenha aplicado indefinidamente o método científico. A razão para isso é que ele não obteve o necessário apoio social para enveredar por tais sendas. Numa dogmática tomada pelo dedutivismo, Pontes procurou indicar outros rumos, mas não obteve a recepção que almejava. Como sempre considerou a colaboração o traço distintivo do espírito científico, jamais conseguiria sozinho mudar todo o Direito Brasileiro.

Para tanto, foi necessário empreender uma pesquisa documental, que partisse dos textos do autor; dedutiva, esclarecendo as relações conceituais; e histórica, que procurasse reconstituir algo do momento em que esta proposta metodológica foi apresentada.

Como resultado da pesquisa, concluiuse que Pontes de Miranda encontrava uma série de métodos na Ciência do Direito, mas os considerou todos por demais subjetivos, de modo que repropôs um em terras nacionais, o método científico.

As questões que nortearam a pesquisa e que resultaram nas seguintes seções são:

a) por que propor um novo método (seção 2);

b) por que os métodos de então eram insuficientes (seção 3);

c) qual a premissa fática para a instituição deste novo método (seção 4);

d) quais as etapas deste novo método (seção 5).

\section{O PROBLEMA DA INTERFERÊNCIA DA VONTADE NA ELABORAÇÃO DO DIREITO}

Assim como toda informação pode ser 
encarada como uma resposta a uma pergunta, toda proposta também deve ser vista como uma tentativa de resolução de um problema e, no campo teórico, isso não é diferente. A respeito do método, portanto, é necessário reconhecer que ele possui algum objetivo a esclarecer e o método jurídico, algo jurídico por elucidar.

No início do século XX, período de consolidação da Primeira República (18891930), o debate acadêmico jurídico era primeiramente metodológico, o que acabava por interferir na maneira mesma de como se estudar o Direito e, numa época em que a corrente crescente era o naturalismo jurídico, o objetivo de então era equiparar a Ciência do Direito às ciências naturais.

Entretanto, mais do que uma luta ideológica, este movimento possuía algo de honesto, porque, ainda que se possa alegar uma movimentação elitista por um novo regime, é difícil aceitar que isso se desse apenas e somente para a obtenção do poder. No presente caso, Pontes de Miranda não rompe com a geração dos jusnaturalistas por um mero e simples capricho, mas apresenta razões e fundamenta uma nova visão do direito que continua partindo da natureza, mas não de uma natureza imaterial. $\mathrm{O}$ naturalismo jurídico se apresentava como uma refutação simultânea ao jusnaturalismo e ao conceitualismo (LOPES, 2014, p. 48).

Os traços centrais do naturalismo jurídico ou empirismo jurídico brasileiro - nem todos presentes simultaneamente em seus representantes brasileiros, como Pontes de Miranda e Clóvis Bevilaqua - são: (a) o caráter unitário das ciências, a dizer, a renúncia à separação neokantiana entre mundo do ser e do dever-ser; (b) a filosofia como filosofia da ciência ou síntese de todas as ciências; e (c) o evolucionismo na biologia e sociologia (LOPES, 2014, p. 126). O objeto da Ciência do Direito seria, nesse sentido, um fato social empírico, e o seu método pressupõe alguma forma de verificação empírica.

Então, havia algum problema, alguma situação que o jusnaturalismo não teria conseguido resolver e que o naturalismo arrogou para si a fim de tentar dissolvê-la, e a isto chama Pontes de Miranda (2000, t. 4, p. 103) de problema do regalismo (do latim rex, que significa rei); o problema do regalismo também pode ser chamado de problema do voluntarismo subjetivista (MIRANDA, 2000, t. 4, p. 109) e consiste na identificação das regras jurídicas com a vontade do soberano: "Um dos preconceitos que mais envilecem a doutrina do Estado é o que julga uma, central, a fonte do poder" (MIRANDA, 2000, t. 4, p. 140).

Ante a expulsão do sobrenatural da discussão teórica e preservação do voluntarismo no campo político, a discussão metodológica da primeira República tinha que eliminar seu segundo rival, este regalismo.

\section{AS TENTATIVAS FRUSTRADAS DE RESOLUÇÃO PELOS MÉTODOS SUBJETIVISTAS}

Havia então uma série de métodos propostos e, para levantar o seu, foi necessário que Pontes os enfrentasse um a um; este artigo delineia suas críticas a sete deles: o método escolástico (seção 2.1), o racionalista (seção 2.2), o sistemático (seção 2.3), o analógico (seção 2.4), o institucionalista (seção 2.5), o histórico (seção 2.6) e o pragmático (seção 2.7).

\subsection{Método escolástico}

O mais antigo método com que Pontes se depara é o que chama de escolástico e é, sem sombra de dúvidas, aquele contra o qual mais se insurge, tanto por sua ligação com a corrente jusnaturalista, como por sua adoção irrestrita no território nacional, onde o jusnaturalismo foi a corrente dominante durante todo o século XIX 
(LOPES, 2014, p. 19-29; MARCOS, 2014, p. 145-215). Com a República de 1891, o aparato institucional do Império começou a ser convertido em republicano, e uma movimentação ideológica (o naturalismo) precisou justificar esse movimento, de modo que Pontes continua a geração dos que pretendem expurgar do Direito brasileiro a inspiração sobrenatural (metafísica) e religiosa.

Antes, porém, de delinear sua crítica ao jusnaturalismo, é necessário destacar um ponto: na formulação de suas objeções à Escolástica, Pontes se baseia no revisionismo histórico do século XIX, que procurou comprovar as acusações feitas pelos iluministas do século XVIII à Igreja; sabe-se, entretanto, que muitas dessas críticas foram motivadas por um anticlericalismo que não necessariamente se baseava nos fatos, mas numa discriminação contra a estrutura eclesiástica. ${ }^{4}$ Contudo, este trabalho não tem por fim avaliar a pertinência das críticas de Pontes ao jusnaturalismo, mas sublinhar, nesta seção, a maneira com que ele encarava as demais alternativas ao problema do regalismo e que lhe motivou a defender o método científico frente aos demais (seção 4).

A grande crítica que Pontes levanta ao escolasticismo pode ser subsumida na crítica geral dos métodos não científicos: o subjetivismo. Tal crítica se aproxima das reflexões do segundo Jhering e do seu conceito voluntarista de lei: "o direito não pode mais ser compreendido como uma expressão da vontade ou pensamento do legislador histórico, mas, sim, como expressão da vontade de uma comunidade jurídica [...]" (MATOS, 2016, p. 22). Nesse sentido, Pontes assume o mesmo ponto de partida dos principais autores da teoria do direito do século XX, como Gustav Radbruch e Hans Kelsen, no sentido de que parte do debate em torno do conceito voluntarista de direito,

\footnotetext{
4 Acerca disso, cf. Rodney Stark (2016, passim); Adeodato (2003, p. 314).
}

inspirado pelas críticas do segundo Jhering (SCHRÖDER, 2012, p. 281).

Ora, o problema do regalismo consiste em utilizar um critério individual, subjetivo, particular, para avaliar, derivar e justificar o Direito (cf. seção 1). Definir o Direito a partir de uma causa eficiente (seja ela Deus, seja ela o Estado), ${ }^{5}$ isto é, quem o declara, não é suficiente para Pontes, porque, se o Direito depende do alvitre de alguém, ele pode mudar, e essa mudança não tem justificativa senão que o alvitre do soberano mudou. E essa mudança pode ser deletéria à sociedade, porque ela não tem por base a sociedade mesma, mas as paixões do governante. Ademais, isso torna o conhecimento jurídico completamente contingente ou nãocientífico e, por conseguinte, submisso à crítica de von Kirchmann. ${ }^{6}$

O problema do jusnaturalismo estaria então em que ele também, como todo método subjetivo, não partiria do real, da sociedade, mas impor-se-ia sobre ela. Também o jusnaturalismo racionalista do século XIX deveria ser considerado subjetivista, porque ele faria depender o Direito do que acreditavam os

\footnotetext{
5 Aristóteles defendia que a composição das coisas se fazia com quatro causas: a material, a formal, a eficiente e a final. Tome-se o exemplo de uma mesa e seu carpinteiro. A madeira com que faz a mesa é a causa material e a projeção que tinha da mesa, sua causa formal. A causa eficiente é o carpinteiro mesmo, cujo trabalho produziu a mesa que antes era apenas uma ideia. A causa final é o propósito da mesa, aparar objetos. O problema do regalismo é, portanto, acreditar que o que faz o Direito é o legislador, assim como quem acreditasse que o que faz a mesa é o carpinteiro. Assim como uma mesa não é uma mesa por ter sido feita por um carpinteiro, mas por ser uma mesa, o Direito não é Direito por ser emitido pelo Estado.

${ }^{6}$ O jurista e político Julius Hermann von Kirchmann proferiu, no ano de 1847, a sua famosa palestra Die Wertlosigkeit der Jurisprudenz als Wissenschaft ("A Falta de Valor da Jurisprudência como Ciência"), cujo argumento central consiste em afirmar que as principais características do objeto da Ciência do Direito são a contingência e variabilidade. Por conseguinte, seria vã a tentativa de construir uma ciência de respeito a partir de um objeto sem rigidez. Cf. Kirste (2013, passim); Souza (1994, p. 97-101).
} 
jusnaturalistas. Suas crenças podiam estar muito bem fundadas, mas não deixavam de ser crenças e, portanto, seriam dados subjetivos, que dependem do sujeito, pois a crença de um não implicaria que outrem também cresse. O Direito, então, não podia partir de uma crença, mas de um dado físico, real, científico.

Ao contrário do racionalismo (seção 2.2), o jusnaturalismo não peca pela mudança, mas pela estagnação excessiva. Ao invés de reconhecer os novos estágios da sociedade, ele se prende ao passado. ${ }^{7}$ Trata-se de uma crítica próxima a que será feita quando da análise do método histórico (seção 2.6): o prender-se ao passado.

Há, de fato, um elemento prudencial no manter a situação, porque a sociedade está de certo modo acostumada a ela. Contudo, a prudência é aparente, porque, ainda que no momento essa manutenção pareça benéfica, ela traz consequências futuras deletérias. ${ }^{8}$ Significa então que o escolasticismo padeceria de uma preocupação com o passado que o impedisse de seguir em frente.

De um lado, pode-se ver que o escolasticismo padece de um preconceito tradicionalista e, doutro, de um preconceito abstracionista. $\mathrm{O}$ preconceito tradicionalista consiste em manter regras jurídicas por sua antiguidade e venerabilidade, erro próximo ao do método histórico (seção 2.6). O preconceito abstracionista consiste em se preocupar com a coerência lógica dos conceitos jurídicos sem se preocupar, porém, com sua correspondência nos fatos, no real: "[a Escolástica] trabalha com certo aparelho de conceitos e trata-os como se fossem ídolos" (MIRANDA, 2000, t. 4, p. 90).

\footnotetext{
7 Nesse sentido, para Pontes, o jusnaturalismo seria uma espécie de conservadorismo no âmbito da teoria do direito. Para esta concepção de conservadorismo, cf. MacIntyre (2001, p. 372).

8 "Manter $o$ que é constitui regra de prudência; porém nem sempre de sabedoria" (PONTES, 2000, t. 4, p. 121).
}

E uma prática do método escolástico que teria sido preservada consiste na adoção e interpretação da lei posta pelo fato de ter sido posta, seja por Deus, seja pelo governante: “está o velho método em inteira coerência com a mentalidade da época: a leitura dos homens de então, a principalíssima de todas, era a Bíblia, e não os livros profanos, de que pudessem discordar" (MIRANDA, 2000, t. 4, p. 96). De fato, a prática do comentário (bíblico ou legislativo) é escolástica por excelência (MARGUTTI, 2013, 118). É claro que a Escolástica não se reduziu a um comentário acrítico de textos. Isto pode ser constatado com facilidade na Summa Theologiae de São Tomás de Aquino, que não concorda em tudo com seus antecessores. De fato, o problema da Escolástica não teria sido tanto de aceitar sem discutir, mas em desconsiderar as mudanças sociais ao legislar. Portanto, a aplicação do comentário à lei como se fosse a Bíblia teria sido o grande problema da Escolástica.

É claro que, na medida em que a lei houvesse sido promulgada por Deus, como se podia argumentar no regime imperial, quando se admitia que o imperador detinha o poder temporal por mandato divino, esse tipo de prática podia e até devia ser utilizada. Porém, na medida em que o Brasil se torna uma república laica em que o governante tem seu poder por mandato popular, considerar suas leis como declarações definitivas do Direito mostra apenas que o imperador mudou, mas as roupas continuaram as mesmas.

Portanto, a crítica de Pontes ao escolasticismo pode ser sintetizada da seguinte maneira: o problema do escolasticismo reside em que ele tende a manter normas desconformes à realidade, porque ultrapassadas, e sem derivá-las da realidade. Ou seja, o escolasticismo tentaria manter o passado sem tirar as normas dos fatos. Além disso, ele mantém o regalismo na medida em que o governante declara as leis como se 
fosse Deus.

Num mundo que se diz secular, é curioso que uma figura como a do governante temporário tente declarar normas divinas. O Direito que advém do Estado não se diferencia muito do Direito que advém de Deus, já que ambos dependem da vontade de alguém. Entretanto, se o objetivo do republicanismo era eliminar o elemento subjetivo, não se pode mais considerar o Estado como o emissor das leis. Seu papel teria de ser outro, mas esse ponto será expandido na seção 4 .

\subsection{Método racionalista}

Em relação ao método escolástico, o método racionalista guarda uma semelhança, mas apresenta uma diferença.

A semelhança reside em que também o método racionalista, por ser conceitualista, não deriva suas normas das relações e fatos sociais, mas da letra da lei, para preservar a coerência lógica dos textos. É algo muito similar ao que Kelsen (2009, passim) procura fazer. Entretanto, e por causa de seu fundo histórico, o método racionalista se projeta para o futuro, enquanto o escolástico se volta para o passado.

Enquanto o escolasticismo teria um quê de tradicionalista, o racionalismo teria um quê de revolucionário. E o exemplo que Pontes levanta é o da tentativa de extinção da família na França revolucionária, como Le Play denunciou (MIRANDA, 2000, t. 4, 112-113).

Então, o problema do método racionalista é que

tudo confia à razão, à lógica, ao a priori, e está certo de que os mais complicados problemas do mundo pode resolver com alguns momentos de reflexão, de modo que estabelece a discordância (e raro a ocasional coincidência) entre a pura obra do espírito e o real a que se destina (MIRANDA, 2000, t. 4, p. 82).

\subsection{Método sistemático}

O método sistemático, ou construtivo (MIRANDA, 2000, t. 4, p. 16), é também chamado de romanístico-construtivo (MIRANDA, 2000, t. 4, p. 91), ou lógicoconstrutivo (MIRANDA, 2000, t. 4, p. 130). Aproxima-se do racionalismo e do escolasticismo por seu cuidado conceitual. Contudo, afasta-se de ambos respectivamente por the faltar um fundo sobrenatural e um fundo político (revolucionário).

Então, seus olhos não estão voltados para o passado, mas para o encadeamento de ideias e conceitos. E é este o seu problema, pois, se ambos pecavam por se concentrar no passado (escolasticismo) e no futuro (racionalismo), o construtivismo despreza absolutamente o tempo em prol de uma pureza conceitual. Contudo, o direito não é feito de conceitos e projeções mentais, mas de relações sociais, motivo por que o cuidado conceitual, por mais que importante, não esgota o trabalho científico e, na verdade, pressupõe-no e antecede: "O primeiro cuidado da atividade sociológica e, particularmente, jurídica, é o descobrimento ou, pelo menos, o avivamento das relações existentes, dos dados; depois vem a comparação e, pois, os julgamentos de identidade, semelhança e diferença" (MIRANDA, 2000, t. 4, p. 50).

Desse modo, o método sistemático peca por seu apriorismo que lhe impede chegar ao real. E este apriorismo é subjetivista, porque põe o direito inteiro dentro da formulação e estruturação mental de conceitos. Mas o Direito não é um simples trabalho de lógica.

\subsection{Método analógico}

Pontes de Miranda fala da analogia em dois sentidos distintos, mas similares. 
O primeiro sentido é a analogia linguística, que tem uma função pedagógica e é utilizada para ilustrar um argumento. Num determinado ponto da obra, Pontes de Miranda (2000, t. 4, p. 98) compara o conhecimento obtido pela análise das relações sociais a uma molécula, e não a um átomo, porque o estudo das relações sociais não chega aos componentes últimos da realidade, motivo por que não se pretenderia a uma monadologia do Direito, mas a componentes próximos, relações entre termos que não necessariamente são os últimos.

O segundo sentido é a analogia enquanto subsunção. Neste sentido, a analogia pode ser retirada da análise de relações sociais e pode, portanto, revelar uma lei natural que as reja, sendo, portanto, incentivada sua procura. No entanto, ela pode também ser tirada de leis estatais, analogia essa que é vedada em Direito Penal. Esta última analogia é típica dos três métodos já abordados (escolástico, racionalista e sistemático) e deve ser, portanto, evitada a todo custo, porque não acompanha o mundo, mas o texto, e o texto pode não se adequar à realidade (MIRANDA, 1928, p. 145).

Quanto à analogia das relações sociais, e não a dos textos legais, existem duas espécies: a completa e a incompleta. A analogia completa é a subsunção de lei natural já induzida, e a analogia incompleta, a comparação que evidencia a diferença entre relações. A primeira gera um efeito prático (a aplicação de lei natural induzida) e a segunda, não. Entretanto, por ser incompleta, seu destino é se completar, ou seja, induzir a lei natural. ${ }^{9}$ Assim, por mais que as duas se diferenciem quanto aos efeitos, sua diferença é quantitativa e transitória por conta da falta de dados.

O único risco real da analogia tirada das relações sociais é "não ser análogo o elemento que se crê substancial, mas o maior deles é o de

\footnotetext{
${ }^{9} \mathrm{O}$ sentido de lei natural aqui empregado é naturalista, e
} não jusnaturalista. não existir em nenhum dos dois objetos tal elemento de comparação" (MIRANDA, 2000, t. 4 , p. 109), mas isso aparenta ser mais um erro de juízo do que um risco do processo analógico mesmo.

Portanto, a analogia enquanto subsunção é um procedimento mental, que, embora importante, não é suficiente para o Direito, porque, ainda que caibam operações mentais para a revelação do direito, como a observação e a experimentação internas (cf. respectivamente seções 4.1. e 4.3.), elas não são suficientes, pois o Direito todo não é uma construção lógica, não é um objeto mental, mas um dado encontrado no real.

O método analógico é subjetivo se se mantiver estritamente lógico e formal. Por isso, pode e deve ser assimilado ao método científico, mas não pode aglutiná-lo.

\subsection{Método institucionalista}

Com método institucionalista, Pontes se refere à escola sociológica francesa a que pertence Émile Durkheim e seus seguidores.

Pontes reconhece que são exemplares da descrição, a qual é vital para o trabalho científico de observação (MIRANDA, 2000, t. 4, p. 112), mas anota que lhes faltaria a prática da indução (cf. seção 4.2): "Em Émile Durkheim, o método é puramente descritivo ou, pelo menos, só remota e acidentalmente indutivo" (MIRANDA, 2000, t. 4, p. 21).

Além disso, queixa-se de que a escola sociológica francesa é pouco interdisciplinar:

Não se apoia no conjunto das ciências que mais fundamentalmente interessam ao sociólogo; não é matemática, nem biológica, a sociologia deles; não contém física social, como a de Quetelet, nem social-biologia, como a dos alemães de hoje, - é mais comtiana e, posto que mais rigorosa e senhora de si, igualmente metafísica (MIRANDA, 2000, t. 4, p. 21). 
Quanto à interdisciplinaridade, trata-se de pressuposto da atividade científica, pois "todas as ciências servem ao mesmo tempo a cada ciência" (MIRANDA, 2000, t. 4, p. 116).

Quanto à acusação de metafísica, Pontes de Miranda (2000, t. 4, p. 21) se refere à alegação de Emmanuel Lévy de que as teorias sociais (econômicas, jurídicas, históricas) são estados sociais de consciência, e é este o subjetivismo do método institucionalista.

É um subjetivismo próximo do subjetivismo construtivista, porque também lhe falta uma comunicação maior com a maneira como os fatos jurídicos ocorrem em sociedade e por seu apreço à lei, o texto escrito. Contudo, diferencia-se do construtivismo por que tem pelo menos uma comunicação algo maior com os fatos, na medida em que analisa as instituições, enquanto o construtivismo se prende ao texto. ${ }^{10}$ Entretanto, as instituições não são todo o direito, mas sua parte mais visível, externa: "O mesmo invólucro institucional, o mesmo texto de lei, pode ter sentidos diferentes em dois ou três períodos de vigência" (MIRANDA, 2000, t. 4, p. 53).

\subsection{Método histórico}

Após o método escolástico (seção 2.1), o método histórico é o mais criticado por Pontes, porque ele incorre no mesmo fixismo daquele, só que sem o fundo sobrenatural. Então, também o historicismo se volta para o passado, mas, ao contrário do método escolástico, tem a pretensão científica de prever o futuro. Deste modo, enquanto o escolasticismo pretende manter regras já vigentes, o método histórico pretende que nas regras vigentes haja sempre o germe das regras futuras: "ater-se ao que provia, sem investigar se ainda deve prover, o que condena o direito à imobilidade causadora de males sem

\footnotetext{
10 "Nem todo o direito positivo está nos textos" (PONTES,
} 2000, t. 4, p. 145). contas às vezes graves" (MIRANDA, 2000, t. 4, p. 82).

$\mathrm{Na}$ verdade, o método histórico é utilíssimo ao Direito, mas ele não pode ser considerado o único. Como o método analógico, é uma técnica necessária, mas não suficiente: “o método histórico [é] parte e não todo o método jurídico; um dos processos, e não o processo da investigação científica" (MIRANDA, 2000, t. 4, p. 119).

Seu ponto de partida, os documentos (MIRANDA, 2000, t. 4, p. 116), o torna como que uma técnica própria da observação indireta, primeira fase do método científico (seção 5.1).

$\mathrm{O}$ valor do método histórico reside no ensinamento que fornece a respeito de como a sociedade se desenvolveu (MIRANDA, 2000, t. 4, p. 116), mas não significa que o presente corresponda ao passado e é no menosprezo do presente que está o risco do método histórico: "No direito somente se considera e se atende ao presente, porque o próprio passado apenas é invocado para se mostrar a fonte ou a concordância do preceito moderno. E tanto é certo isto que não se deve perguntar o que é preciso para ser justa a sentença, mas para o ser hoje" (MIRANDA, 2000, t. 4, p. 117).

A dificuldade, contudo, de aplicar esse argumento de Pontes está em como definir o presente, na medida em que a conscientização do momento vivido o torna passado. Pode-se com certeza alegar que o passado é o ocorrido há alguns anos, décadas ou séculos, mas não há entretanto uma justificativa em sua obra para desprezar os minutos, as horas e os dias. De uma parte essa objeção parece pueril, pois ninguém fala deste passado próximo quando trata de História, mas a questão é que a externalidade legislativa do fenômeno jurídico tão desprezada por Pontes pertence a esta história próxima, e seu desprezo é uma maneira de se esquivar de um dado que se impõe: também as escolas historicista e institucionalista são forças que 
atuam na formulação do Direito.

E o próprio Pontes, ao escrever seu livro, é também apenas mais um personagem que procura influenciar o curso das coisas. Com efeito, sua crítica a ver o futuro no passado é válida e seu reconhecimento de que a História não precisa por isso ser defenestrada, também. Entretanto, na crítica do método histórico é onde Pontes encontra mais dificuldades para defender o método científico, talvez porque ele mesmo tenha empregado o método histórico (MIRANDA, 1928), mas, e sobretudo, porque ele não fornece um critério sobre como efetuar o paralelismo entre passado e presente e empregar com eficácia o método histórico, por mais que considerado só uma parte do método científico.

Por isso, empregar apenas o método historicista é um modo de subjetivismo; afinal, pretende-se superior e único.

\subsection{Método pragmático}

Se o problema do método escolástico (seção 3.1) reside em desprezar o presente e o futuro em favor do passado, do método racionalista (seção 3.2), em desprezar o presente e o passado em favor do futuro, do método sistemático (seção 3.3), em desprezar passado, presente e futuro em favor de conceitos, o problema do método pragmático consiste em desprezar passado e futuro em favor do presente.

Também chamado de "método do jurista prático" (MIRANDA, 2000, t. 4, p. 16), este método, chamado pelo artigo de pragmático, é um tanto casuísta, porque busca o critério de discernimento do Direito na maneira com que os casos são julgados no tribunal. Então, como o método institucionalista (seção 2.5), ele padece do problema de procurar o Direito em apenas uma forma de manifestação, quando há muito mais: "Os atos jurídicos, os atos da vida, que não vão aos tribunais, são o maior repositório do direito aplicado" (MIRANDA, 2000, t. 4, p.
139). Contudo, enquanto o método institucionalista procura nas instituições em geral, o método do jurista prático é ainda mais míope, pois se contenta com as leis e com as decisões.

Além disso, é subjetivo, porque faz com que o Direito dependa do alvitre, senão do legislador, do juiz. E, como se não bastasse, gera um grupo de juristas que compreendem o funcionamento do aparelho estatal, mas não conhecem o direito mesmo: "lidam com o direito, como os mecânicos, os práticos, lidam com a eletricidade: sem a compreender" (MIRANDA, 2000, t. 4, p. 132).

\section{DEMOCRATIZAÇÃO DA REVELAÇÃO DO DIREITO}

Com exceção do método analítico (seção 2.4) e do método histórico (seção 2.6), cujas críticas são as mais faltas, Pontes demonstra bem quais as suas razões para não se conformar com os métodos usados à época, seu subjetivismo que redundaria no tão temido regalismo.

Consequentemente, ele precisa propor um método cujo critério não dependa da vontade, mas de algo igualmente constatável por terceiros, ainda que não sobrenatural; a isto ele chama de real (MIRANDA, 2000, t. 4, passim). A identificação do real, contudo, será abordada posteriormente.

$\mathrm{Na}$ presente seção, o necessário é indicar a concepção fragmentária de conhecimento e a solução pela formação de uma comunidade jurídica científica e solidária pela "democratização dos processos de revelação do direito" (MIRANDA, 1928, p. 36-38).

A concepção fragmentária do conhecimento é uma premissa constante do pensamento de Pontes, seja ao considerar o homem como parte da natureza que estuda (MIRANDA, 2000, t. 3, p. 19), seja ao 
considerar a limitação dos sentidos humanos, que o impedem de abarcar o todo (MIRANDA, 1999, p. 64 et seq.). Deste modo, existe uma fronteira física entre o homem e o mundo, que é sua impotência, a qual só pode ser contornada pelo voltar-se insistente ao real, não como quem o domine, mas como quem pertence a ele e o observa.

Desse modo, o primeiro ponto necessário a um método objetivo é que o ponto de partida não seja a lei, mas as relações sociais; o segundo ponto é, por sua vez, a aplicação de um mesmo método. Desta maneira se cumprem os dois requisitos de uma ciência verdadeira: mesmo objeto e mesmo método (ADLER, 1937, p. 3-30).

Só que esta aplicação não deve ser restrita a uma classe de juristas, os doutrinadores, por exemplo, mas deve ser ampliada a todos os membros que interferem e trabalham com o Direito: legislador, doutrinador e magistrado.

A este princípio, Pontes de Miranda (1928, p. 36-38) chama de lei de democratização dos processos de revelação do Direito. E ela é necessária na medida em que o conhecimento, por ser fragmentário, não pode ser todo abarcado por uma só pessoa, mas é necessário que várias colaborem umas com as outras. Dessa maneira foi possível, por exemplo, a revolução da Física nas primeiras décadas do século XX.

Tal abertura da revelação do direito significa que não só o Estado pode declará-lo, mas o estudioso também. Entretanto, isso não importa em que cada pessoa possa aplicar a lei que bem entender, pois a lei que bem entender precisa estar comprovada nos fatos, e sua aplicação depende ainda da concordância da comunidade científica, pois o objetivo do método científico é evitar o regalismo; se o método científico levasse à aplicação de normas pelo alvitre do conhecimento de um indivíduo, significaria que o método científico não seria objetivo, mas subjetivo.

Além disso, a democratização acarreta a aplicação da norma que mais se adeque àquela sociedade naquele momento, porque "os fenômenos sociais não são arbitrariamente modificáveis" (MIRANDA, 2000, t. 4, p. 56).

Portanto, o pressuposto material de aplicação do método científico é a colaboração generalizada dos juristas todos (legislador, doutrinador e juiz). A pesquisa científica, então, pressupõe uma solidariedade entre os sujeitos implicados, que reconhecem sua insuficiência de compreensão e alcance do todo e, em compensação, auxiliam-se uns aos outros para que todos, juntos, consigam uma melhor imagem da realidade, uma melhor compreensão do mundo.

\section{AS TRÊS FASES DO MÉTODO CIENTÍFICO}

Pelo exposto, o método científico precisa da colaboração irrestrita da comunidade jurídica. Essa colaboração não deve ser feita de qualquer maneira, mas de acordo com um método que permita a todos verificarem os resultados de todos, e este é o método científico, que se desenvolve em três etapas: observação (seção 4.1), indução (seção 4.2) e experimentação (seção 4.3).

\subsection{Observação}

A observação é a primeira etapa do método científico (MIRANDA, 2000, t. 4, p. 25 e 115), consiste na "adaptação do pensamento aos fatos" e resulta na colheita de dados (MIRANDA, 2000, t. 4, p. 112), que podem servir de base para induções de regras jurídicas, ou casos concretos, nos quais se aplicam as regras jurídicas induzidas. Portanto, os efeitos da observação são sentidos em todas as fases da elaboração jurídica: no momento pré-legislativo 
(doutrinário), porque fornece o material de indução das regras jurídicas; no legislativo, que externaliza a regra jurídica induzida; no póslegislativo (exegético), porque o caso concreto também é observado. Trata-se de atividade natural do homem, sem a qual não pode pensar, pelo fato de que é graças à observação que o homem tem com que pensar. Além disso, não há contraindicação à observação, porque "quanto mais se observa mais se sabe" (MIRANDA, 2000, t. 4, p. 111).

A observação se distingue conforme a origem do dado e conforme a sucessão de pessoas que o examinou.

Quanto à origem do dado, pode ser interna (introspectiva) ou externa (extrospectiva), porque os dados ou são psicológicos, ou são físicos. A observação de dados psicológicos é chamada interna, ou introspectiva, porque os dados são colhidos da psique (da mente) do próprio sujeito observador, enquanto a observação de dados físicos é chamada externa, ou extrospectiva, porque os dados são colhidos de fora do sujeito observador. Ainda assim, esta diferença é acidental, e não essencial, ou seja, importa em graus, e não em tipos de observação por dois motivos: em primeiro lugar, não há diferença essencial entre dados físicos e dados psicológicos; em segundo lugar, ainda que mude a origem do dado, o observador não muda (MIRANDA, 2000, t. 4, p. 110-111).

Não obstante, a observação interna deve ser feita com especiais rigor e cautela na Ciência Jurídica, porque sua verificabilidade é reduzida (MIRANDA, 2000, t. 4, p. 111).

Quanto à sucessão de pessoas examinadoras do dado, a observação pode ser direta ou indireta. A observação direta é feita pelo sujeito observador sem a opinião prévia de alguém sobre o mesmo dado, pois quem o colhe é o sujeito observador, enquanto a observação indireta recai sobre um dado colhido por outrem.
Nesse sentido, é possível chamá-las respectivamente de observação originária e observação derivada.

Um grande repositório de observações originárias eram as monografias científicas e são, atualmente, os artigos científicos. $\mathrm{O}$ exame desses repositórios consiste numa experiência derivada, porque a colheita de dados não foi feita pelo leitor, mas pelo autor, que os publica, tornando-os comuns à comunidade científica, para que ela possa auxiliá-lo no trabalho de interpretação, pois o método científico não termina na descrição. Um passo posterior é necessário: a discussão entre os cientistas (MIRANDA, 2000, t. 4, p. 111-112).

\subsection{Indução}

A segunda etapa do método científico consiste na indução, que já é conhecida do pensamento filosófico desde Aristóteles (2010, p. 520-521).

Contudo, a indução aristotélica, que Pontes de Miranda (2000, t. 4, p. 58) também chama de "escolástica", é impraticável, porque Pontes a acusa de tentar enumerar "todos os fatos e todos os indivíduos de determinada espécie".

Certamente, a enunciação de uma lei posteriormente à consulta de todos os entes pertencentes ao gênero que se estuda é impossível, seja pelos entes passados, seja pelos futuros, mas, mais do que isso, pela impossibilidade de se dizer que todos foram consultados dada a fragmentariedade do conhecimento humano (seção 3).

Em resposta, Pontes defende uma indução científica, já proposta por Francis Bacon, que elabora as três tábuas modernas da indução: a tábua de presenças, a tábua de ausências e a tábua de comparações.

A tábua de presenças consiste na identificação de um evento dadas determinadas circunstâncias. Por exemplo, registra-se na tábua 
que, sempre que certa pessoa dorme num colchão infestado de ácaros, ela tem reações alérgicas. Pelos dados constantes da tábua se conclui que a pessoa é alérgica a ácaros (existe uma reação, a alergia, dada uma causa, os ácaros).

A tábua de ausências consiste na constatação da ausência do evento em determinadas circunstâncias. Por exemplo, registra-se que uma pessoa sofre de coriza por causa de um vírus. Então, ela toma o medicamento prescrito, a coriza desaparece e se constata que a ausência da coriza dependia da ausência do vírus no organismo.

A tábua de comparações consiste na constatação de que, em certas circunstâncias, o evento ocorre e noutras, não. No mesmo exemplo da coriza, nota-se que, com certo medicamento, o vírus morre; com outro, não.

John Stuart Mill propôs uma quarta tábua de indução, a tábua dos restos, na qual se constata a gradação de um determinado evento pela minoração de suas já identificadas causas. Enfim, tome-se o exemplo da Síndrome da Imunodeficiência Adquirida, para a qual não há cura. Existe uma série de medicamentos que permite uma melhor coexistência com os sintomas, mas a tábua registra que nenhuma das causas intencionalmente provocadas (a ingestão de remédios) consegue exterminar o vírus do organismo.

Pontes de Miranda (2000, t. 4, p. 59) chama cada uma dessas tábuas de método de concordância (tábua de presenças), método de diferença (tábua de ausências), método das variações concomitantes (tábua de comparação) e método dos resíduos (tábua dos restos).

O objetivo da indução é a revelação de leis não mais derivadas da vontade do legislador e do juiz, mas da constatação fática dos eventos da vida: "Pelo exame dos fatos descobrir e provar as leis que os regem, tal o fim da indução científica, porque a lei não é mais do que a relação constante entre os fatos" (MIRANDA, 2000 , t. 4 , p. 58-59).

\subsection{Experimentação}

A terceira e última fase do método científico é a experimentação, que, como a observação (seção 4.1), pode ser mental ou física (PONTES, 2000, t. 4, p. 130), sendo que a segunda era tida como mais eficiente.

A experiência física consiste na intervenção consciente na matéria e, no Direito, pode ser vista quando uma lei é promulgada e a comunidade política reage a ela. Isto é também uma forma de experiência, na medida em que não se sabe qual a resposta que a sociedade dará. A experiência mental é feita "por abstração, e pela qual, representados os fenômenos em condições simples hipotéticas, procedemos ao exame do que nos interessa" (MIRANDA, 2000, t. 4, p. 135).

Pontes de Miranda (2000, t. 4, p. 130) define a experimentação como uma "observação provocada". Com esta definição parece que a diferença entre observação e experimentação reside em dois traços: a consciência e a interferência no real para a confirmação.

Ele também a considera um processo vital comum ao homem e aos outros animais:

A experimentação não pertence somente ao homem nem tão-somente ao indivíduo humano. Encontramo-la entre outros animais e a observação da vida mental da criança revelanos algo de inato nas suas experiências rudimentares. $\mathrm{O}$ instinto não tem outra explicação, posto que seja diferente da experimentação mental e física, cujo método é o mais seguro e o mais econômico processo para a adaptação do pensamento aos fatos [observação] (MIRANDA, 2000, t. 4, p. 130).

A experimentação, portanto, é um passo para se refinar a observação.

Pareceria haver uma contradição no método científico, pois, se a observação antecede 
ao experimento, como é possível que o experimento auxilie na observação, que é a adaptação do pensamento aos fatos? Assim ocorre, porque, já que o conhecimento é sempre fragmentário e perfectível, o método científico não tem um termo final, mas ele se renova a cada pesquisa, até porque a observação, sua base, é um ato vital do qual o ser humano não pode se esquivar, já que observar é também um emprego dos sentidos, mas um emprego intelectual, motivo por que se diferencia do instinto.

O objetivo da experimentação é também confirmar se a lei induzida a partir da observação ocorre de fato.

Além disso, experimentação é uma prática congênita ao Direito, pois, a cada vez que se declara e aplica uma regra jurídica (legislando, por exemplo), não há certeza sobre os efeitos que ela acabará por trazer (MIRANDA, 2000, t. 4, p. 134).

Por fim, a experimentação pode vir junto com a indução e com fins de indução: "O método inicial é a observação; depois, vem a indução; mais tarde, a experimentação, que, todavia, poderá vir antes da atividade indutiva, em vez de posteriormente, para comprovar os resultados" (MIRANDA, 2000, t. 4, p. 80).

\section{CONCLUSÃO}

Em suma, este artigo pretendeu apresentar o problema que a proposta metodológica de Pontes de Miranda procurava resolver, o regalismo (seção 1); elencar exemplificativamente os métodos de sua época (seção 2); indicar o pressuposto fático de aplicação de seu método, que é a formação de uma comunidade jurídica solidária (seção 3) por meio da democratização da elaboração do Direito (seção 4); e as etapas fundamentais de seu método: observação, indução e experimentação (seção 5).

$\mathrm{O}$ artigo não procurou defender a proposta de Pontes de Miranda, mas demonstrar que, se sua obra dogmática se parece pouco com sua obra teórica, isso não decorre por uma certa esquizofrenia acadêmica, em razão da qual sua prática fosse desligada da teoria, e sim por um pressuposto teórico: o método científico produz resultados coletivamente, de modo que, sem sua adoção por vários intelectuais, não pode ser aplicado a contento.

O problema de implementação do método científico no Direito é reconhecido pelo método mesmo, porque a interferência e a aplicação de regras jurídicas tiradas dos fatos dependem do nível de maturidade da sociedade em questão, e a sociedade brasileira ainda não conta com juristas compromissados a efetuar um trabalho de pesquisa empírica sociológica anterior ao estabelecimento de leis. As leis, pelo contrário, continuam sendo votadas pelo simples alvitre e vontade do legislador.

Então, a primeira conclusão dos resultados apresentados é que somente uma reviravolta completa na maneira com que o Direito é aplicado e pensado permitira a aplicação irrestrita do método científico na revelação do Direito, pois, sem que haja essa reforma no pensamento jurídico, falta o pressuposto de aplicação do método científico, que é a colaboração comunitária (cf. seção 3).

Assim como a reviravolta na Física provocada pela relatividade exigiu o esforço mútuo de uma série de cientistas, também a reviravolta no Direito exigiria que os juristas todos (legisladores, doutrinadores e magistrados) colaborassem entre si. Sem esse diálogo e a eleição de um fim comum, o problema do regalismo é insanável. Seria, portanto, necessário que a cultura jurídica se conscientizasse e se convencesse de que o Direito não é uma questão de vontade, mas de realidade.

Por esse motivo, chega-se também a uma segunda conclusão: Pontes não pretendeu revolucionar sozinho o Direito, mas pretendeu 
apresentar uma forma alternativa de pensá-lo, cuja aplicabilidade não dependia dele, mas de um aval da comunidade jurídica, aval este que falta até hoje, permanecendo o problema do voluntarismo no Direito.

Sumarizados os resultados da pesquisa e apresentadas suas duas conclusões indiretas, a pesquisa pode ser continuada pela (1) avaliação de se as críticas de Pontes eram voltadas aos métodos mesmos, ou se sua interpretação dos métodos estava equivocada, como foi sugerido na seção 2.1; (2) em que consiste a análise das relações sociais; (3) a relação do método científico com a dedução; (4) o papel da comparação no método científico; dentre outros temas.

O presente artigo não pôde se debruçar sobre estas outras questões por questões de objetivo, mas indica os passos seguintes numa pesquisa a respeito de Pontes de Miranda também como uma forma de incentivar sua proposta de uma comunidade de estudiosos em todas as classes jurídicas, justamente o pressuposto da cientificidade que é a solidariedade (seção 4).

\section{REFERÊNCIAS}

ADEODATO, João Maurício. O positivismo culturalista da Escola do Recife. Novos Estudos Jurídicos, v. 8, n. 2, p. 303-326, 2003.

ADLER, Mortimer J. What man has made of man? Chicago, US: [s. n.], 1937. Cap. 1.

ARISTÓTELES. Órganon. $2^{\text {a }}$ ed. São Paulo, SP: EDIPRO, 2010. (Série Clássicos Edipro)

KELSEN, Hans. Teoria pura do direito. $8^{\text {a }}$ ed. São Paulo, SP: Martins Fontes, 2009.

KIRSTE, Stephan. Introdução à Filosofia do Direito. Belo Horizonte, MG: Fórum, 2013.

LOPES, José Reinaldo de Lima. Naturalismo jurídico no pensamento brasileiro. São Paulo, SP: Saraiva, 2014.

MACINTYRE, Alasdair. Depois da virtude: um estudo em teoria moral. Tradução de Jussara Simões. Bauru, SP: EDUSC, 2001.

MARGUTTI, Paulo. História da filosofia do Brasil: o período colonial (1500-1822). São Paulo, SP: Loyola, 2013.

MARCOS, Rui de Figueiredo. História do direito brasileiro. Rio de Janeiro: Forense, 2014.

MATOS, Saulo Monteiro Martinho de. A hermenêutica jurídica de Gustav Radbruch. Revista de Estudos Constitucionais, Hermenêutica e Teoria do Direito, v. 8, n. 1, jan./abr. 2016, p. 18-27.

MIRANDA, Francisco Cavalcanti Pontes de. Fontes e evolução do direito civil brasileiro. Rio de Janeiro, RJ: Pimenta de Mello, 1928.

MIRANDA, Francisco Cavalcanti Pontes de. Systema de Sciencia Positiva do Direito. Campinas, SP: Bookseller, 2000. Quatro tomos.

SCHRÖDER, Jan. Recht als Wissenschaft. $2^{\mathrm{a}}$ ed. Munique: Beck, 2012. 
SOUZA, Daniel Coelho de. Introdução à ciência do direito. $6^{\mathrm{a}}$ ed. Belém, PA: CEJUP, 1994.

STARK, Rodney. Bearing False Witness: debunking centuries of anti-catholic history. Pennsylvania: Templeton Press, 2016.

Recebido em: 22/09/2017

Aceito em: 20/08/2018 
